\title{
Detection of human papillomavirus in branchial cleft cysts
}

\author{
TARO IKEGAMI $^{1 *}$, TAKAYUKI UEHARA ${ }^{1 *}$, ZEYI DENG $^{1,2}$, SHUNSUKE KONDO $^{1}$, \\ HIROYUKI MAEDA ${ }^{1}$, ASANORI KIYUNA ${ }^{1}$, SHINYA AGENA ${ }^{1}$, HITOSHI HIRAKAWA ${ }^{1}$, \\ YUKASHI YAMASHITA ${ }^{1}$, AKIRA GANAHA ${ }^{1}$ and MIKIO SUZUKI ${ }^{1}$ \\ ${ }^{1}$ Department of Otorhinolaryngology, Head and Neck Surgery, Graduate School of Medicine, \\ University of The Ryukyus, Okinawa 903-0215, Japan; ${ }^{2}$ Department of Otorhinolaryngology, Head and Neck Surgery, \\ Zhujiang Hospital, Southern Medical University, Guangzhou, Guangdong 510280, P.R. China
}

Received March 1, 2017; Accepted May 23, 2017

DOI: $10.3892 / \mathrm{ol} .2018 .8827$

\begin{abstract}
High-risk human papillomavirus (HPV) DNA has been reported to be present in branchial cleft cysts, but further information is required to clarify the role of HPV infection in branchial cleft cysts. The presence of HPV, the viral load and the physical statuses in samples from six patients with branchial cleft cysts were investigated using the polymerase chain reaction (PCR), quantitative PCR, in situ hybridization (ISH) using HPV DNA probes and $\mathrm{p} 16^{\mathrm{INK} 4 \mathrm{a}}$ immunohistochemical analysis. High-risk type HPV-16 DNA was identified in four of the six branchial cleft cysts analyzed. Of the HPV-positive branchial cleft cysts, three exhibited mixed-type integration of HPV. HPV DNA was distributed among the basal-to-granular layers of the cystic wall in ISH analysis, and $\mathrm{p} 16^{\text {INK4a }}$ was weakly expressed in the nuclei and cytoplasm of the same layers in patients with integration. ISH revealed that one patient with episomal-type infection exhibited HPV DNA in the cyst wall and did not express $\mathrm{p} 16^{\mathrm{INK} 4 \mathrm{a}}$. Two patients without evidence of HPV infection exhibited weak p16 $6^{\mathrm{INK} 4 \mathrm{a}}$ expression in the superficial cyst-lining cells of branchial cleft cysts. These results indicate that infection with high-risk HPV types may be common in branchial cleft cysts. In addition, $\mathrm{p} 16^{\text {INK4a }}$ is not a reliable surrogate marker for HPV infection in branchial cleft cysts.
\end{abstract}

Correspondence to: Professor Mikio Suzuki, Department of Otorhinolaryngology, Head and Neck Surgery, Graduate School of Medicine, University of The Ryukyus, 207 Uehara, Nishihara, Nakagami, Okinawa 903-0215, Japan

E-mail: suzuki@med.u-ryukyu-ac-jp

*Contributed equally

Abbreviations: BRCC, branchial cleft cyst; FFPE, formalin-fixed paraffin-embedded; HPV, human papillomavirus; ISH, in situ hybridization; OPC, oropharyngeal carcinoma; PCR, polymerase chain reaction

Key words: human papillomavirus, branchial cleft cyst, viral integration, viral load, in situ hybridization, p16INK4a expression

\section{Introduction}

Branchial cleft cyst (BRCC) is generally accepted to be a congenital cyst derived from the first and second branchial clefts, particularly the second $(1,2)$. BRCC appears as a circumscribed nodular swelling on the side of the neck, with neither an opening in the pharynx nor an external sinus, whereas a branchial fistula communicates internally and/or externally $(1,2)$.

Human papillomaviruses (HPVs) are small non-enveloped doubled-stranded DNA viruses that belong to the Papillomaviridae family (3). To date, more than 200 types of HPV have been identified in clinical samples (3). HPVs are known to infect the epithelium of the skin or mucosa. Mucosal HPVs are divided into two types according to their association with carcinoma: Low-risk and high-risk (4). The 14 types of high-risk HPV of most concern are HPV $-16,-18$, $-31,-33,-35,-39,-45,-51,-52,-56,-58,-59,-66$ and -68 (5). The integration of high-risk HPV DNA into the host genome is a notable step in malignant transformation in uterine cervical cancer $(6,7)$. Viral integration into the host genome often leads to viral $E 2$ gene disruption. Since $E 2$ controls the expression of viral oncogenes $E 6$ and $E 7$ by repressing the viral promoter, integration leads to overexpression of $E 6$ and $E 7$ (8). The E6 oncoprotein is able to disrupt the function of tumor protein p53 (hereinafter referred to as p53), which has anticancer functions, by targeting the $\mathrm{p} 53$ protein for ubiquitination and degradation. Furthermore, the E7 oncoprotein binds and functionally inactivates the retinoblastoma protein $(\mathrm{pRb})$, which regulates the progression from the $G_{1}$ phase to the $S$ phase of the cell cycle. Functional inactivation of pRb by E7 is known to induce upregulation of p16 (also known as cyclin-dependent kinase inhibitor 2A) expression $(9,10)$. These oncoproteins are expressed in high-risk HPV infections, which indicates that they serve a role in the initiation and/or progression of tumors and their interactions may substantially enhance the efficiency of tumor cell immortalization (11).

High-risk HPV DNA detected using the polymerase chain reaction (PCR) and pyrosequencing was previously reported to be present in BRCC: Of 19 BRCCs analyzed, 7 (36.8\%) contained HPV-16 and/or HPV-18 genomic DNA (12). However, HPV DNA could not be identified using in situ hybridization (ISH) in these cases. These disparate findings 
may be due to the differing analytic sensitivities between PCR/pyrosequencing and ISH. Further information, such as viral load and the integration of HPV, is required to clarify the role of HPV infection in BRCC. The aim of the present study was therefore to confirm the presence of HPV infection in BRCC.

\section{Materials and methods}

Patient sample collection. The present study was approved by the Ethics Committee of the University of the Ryukyus (Nakagami, Japan). All patients provided written informed consent to participate prior to surgery. Procedures were performed in accordance with the Declaration of Helsinki. The participants in the present study consisted of 6 patients (3 men and women; age range, 2-29 years) with BRCC and 1 patient with HPV-associated oropharyngeal carcinoma (OPC) with metastasis in the lymph node and cystic formation as the HPV-positive control. Each patient had undergone surgical resection and no other treatment, and pathologists had confirmed the histological diagnoses. Formalin-fixed paraffin-embedded (FFPE; $10 \%$ formalin natural buffer solution at $4^{\circ} \mathrm{C}$ for a 24 -h incubation) and/or fresh-frozen cyst tissues taken from these patients were used for the detection of HPV infection. In addition, cyst fluid from 1 patient was also examined to detect the HPV genome.

Culture of HPV-16-positive CaSki cell line. To obtain HPV-16 positive DNA, an HPV-16-infected cervical cancer cell line, the CaSki cell line, was purchased from the European Collection of Cell Cultures (Salisbury, Wiltshire, UK). The cell line has been tested and authenticated by DNA short tandem repeat profiling by the Japanese Collection of Research Bioresources Cell Bank (Osaka, Japan). The CaSki cells were cultured at a density of $0.7 \times 10^{6}$ cells per $25 \mathrm{~cm}^{2}$ with $5 \mathrm{ml}$ RPMI-1640 containing $10 \%$ fetal bovine serum, $100 \mathrm{IU} / \mathrm{ml}$ penicillin and $100 \mu \mathrm{g} / \mathrm{ml}$ streptomycin. When the culture was near confluence, the cells were detached by cell scraper and placed into a $15-\mathrm{ml}$ tube. The tube was centrifuged at 2,600 $\mathrm{x} \mathrm{g}\left(4^{\circ} \mathrm{C}\right)$ for $5 \mathrm{~min}$, and the supernatant was discarded and pelleted. The cell pellet was stored at $-80^{\circ} \mathrm{C}$ until DNA extraction.

Detection of HPV DNA. The HPV types present in FFPE, fresh-frozen samples and/or fresh-frozen CaSki cell line were analyzed. In the case of FFPE samples, three $10-\mu \mathrm{m}$ thick sections were deparaffinized in xylene and rehydrated in $100 \%$ alcohol. Following air-drying, genomic DNA was extracted using the Gentra Puregene Tissue kit (Qiagen Sciences, Inc., Gaithersberg, MD, USA), as described previously (13). To remove PCR inhibitors (by removing formaldehyde cross-linking between DNA fragments), DNA samples were heated at $100^{\circ} \mathrm{C}$ in $25 \mathrm{mM}$ borate- $\mathrm{NaOH}$ buffer ( $\mathrm{pH} 11.0$ ) for 30 min according to a previously published method (14). Genomic DNA was then re-purified by ethanol precipitation and dissolved in distilled water. In the case of fresh-frozen samples, genomic DNA was extracted as described previously (13). The presence and the integrity of the DNA in all samples were examined by PCR amplification of the $\beta$-globin gene using primers PC04 and GH20 (Table I), as previously described (13). Negative (water) and positive (DNA of HPV-16-positive CaSki cell line) controls were included in each amplification series.

The consensus primer sets GP5+/GP6+ and MY09/MY11 were used to analyze the presence of HPV DNA in PCR (Table I) as described previously (15). When no PCR amplification occurred with $\mathrm{GP}^{+} / \mathrm{GP}^{+}$or MY09/MY11 primers, 10-fold diluted first PCR products were used as template DNA for (auto-)nested PCR using the GP5+/GP6+ primer pair (16). PCR cycling was performed as follows: initial denaturing at $95^{\circ} \mathrm{C}$ for $10 \mathrm{~min} ; 30$ cycles at $95^{\circ} \mathrm{C}$ for $30 \mathrm{sec}, 58^{\circ} \mathrm{C}$ for $1 \mathrm{~min}$, and $72^{\circ} \mathrm{C}$ for $30 \mathrm{sec}$, with a final extension at $72^{\circ} \mathrm{C}$ for 5 min. PCR products of expected size (GP5+/GP6+, $150 \mathrm{bp}$; MY09/MY11, 450 bp) were purified and directly sequenced with an ABI PRISM 3,130xl Genetic Analyzer (Applied Biosystems; Thermo Fisher Scientific, Inc., Waltham, MA, USA) according to the manufacturer's protocol. The sequences were then aligned and compared with those of known HPV types in the GenBank database using BLAST (blast.ncbi.nlm. nih.gov/Blast.cgi).

DNA extracted from FFPE samples may not have been amplified using GP5+/GP6+ or MY09/MY11 primers because of DNA fragmentation during paraffin fixation, which may result in a false-negative result (17). Since the dominant HPV type is HPV-16 in head and neck carcinomas (15), primer sets for the E2, E6 and E7 regions of the HPV-16 sequence were designed to produce small products to prevent a false-negative PCR (Table I). PCR amplification was performed using the GoTaq ${ }^{\circledR}$ Green Master Mix (Promega Corporation, Madison, WI, USA) according to the manufacturer's protocol. PCR was performed as follows: Denaturation at $95^{\circ} \mathrm{C}$ for $15 \mathrm{~min}$, followed by 50 cycles at $95^{\circ} \mathrm{C}$ for $15 \mathrm{sec}$ and $60^{\circ} \mathrm{C}$ for $1 \mathrm{~min}$, and finally $72^{\circ} \mathrm{C}$ for $5 \mathrm{~min}$. PCR fragments of expected size (E2-forward/E2-reverse, $82 \mathrm{bp}$; E6-forward/E6-reverse, $81 \mathrm{bp}$; E7- forward/E7-reverse, $91 \mathrm{bp}$ ) were purified using the Wizard SV GEL and PCR Clean-UP system (Promega Corporation) The purified PCR products were cloned into a PGEM-T easy vector (Promega Corporation) and sequenced using ABI PRISM 3,130xl Genetic Analyzer, as DNA subcloning is an appropriate method for the analysis of DNA sequences of PCR products of $<100 \mathrm{bp}$, when compared with direct sequencing. The sequences obtained were analyzed as aforementioned.

Quantitative (q)PCR analysis of viral load and physical status of HPV-16. To evaluate the viral load and physical status of HPV-16, qPCR was performed as described previously (15). Briefly, primers and TaqMan probes targeting the HPV-16 E2 and $E 6$ open reading frames were used (Table I). The primers and probes recognize the $E 2$ hinge region, which was deleted on HPV-16 integration. Two standard curves for the E2 and E6 genes were created by amplification of 10 -fold serial dilutions $\left(10^{2}, 10^{3}, 10^{4}, 10^{5}\right.$ and $10^{6}$ viral copies) of the plasmid $\mathrm{pB}$-actin containing the complete HPV-16 early region (Addgene, Cambridge, MA, USA). Viral DNA load was assessed by calculating E6 copy numbers. An external standard curve was created using known serial dilutions (0.3, 3, 30 and $300 \mathrm{ng})$ of human genomic placental DNA (Sigma-Aldrich; Merck KGaA, Darmstadt, Germany) for cellular DNA quantification and $\beta$-globin was amplified as described previously $(15,18)$. The amount of DNA was calculated by plotting the Cq values 
Table I. Primers used in the present study.

\begin{tabular}{|c|c|}
\hline Primer name & Sequence \\
\hline \multicolumn{2}{|l|}{ Cloning primers } \\
\hline GP5+ & 5'-TTTGTTACTGTGGTAGATACTAC-3' \\
\hline GP6+ & 5'-GAAAAATAAACTGTAAATCATATTC-3' \\
\hline MY09 & 5'-CGTCCMARRGGAWACTGATC-3' \\
\hline MY11 & 5'-GCMCAGGGWCATAAYAATGG-3' \\
\hline E2-forward & 5'-AACGAAGTATCCTCTCCTGAAATTATTAG-3' \\
\hline E2-reverse & 5'-CCAAGGCGACGGCTTTG-3' \\
\hline E6-forward & 5'-GAGAACTGCAATGTTTCAGGACC-3' \\
\hline E6-reverse & 5'-TGTATAGTTGTTTGCAGCTCTGTGC-3' \\
\hline E7-forward & 5'-CCGGACAGAGCCCATTACAA-3' \\
\hline E7-reverse & 5'-CGAATGTCTACGTGTGTGCTTTG-3' \\
\hline $\mathrm{PC} 04$ & 5'-CAACTTCATCCACGTTCACC-3' \\
\hline GH20 & 5'-GAAGAGCCAAGGACAGGTAC-3' \\
\hline \multicolumn{2}{|c|}{ qPCR primers and Taqman probe } \\
\hline E2-forward & 5'-AACGAAGTATCCTCTCCTGAAATTATTAG-3' \\
\hline E2-reverse & 5'-CCAAGGCGACGGCTTTG-3' \\
\hline E2-probe & 5'-FAM-CACCCCGCCGCGACCCATATAMRA-3' \\
\hline E6-forward & 5'-GAGAACTGCAATGTTTCAGGACC-3' \\
\hline E6-reverse & 5'-TGTATAGTTGTTTGCAGCTCTGTGC-3' \\
\hline E6-probe & 5'-FAM-CAGGAGCGACCCAGAAAGTTACCACAGTTTAMRA-3' \\
\hline$\beta$-globin-F & 5'-TGGGTTTCTGATAGGCACTGACT-3' \\
\hline$\beta$-globin-R & 5'-AACAGCATCAGGAGTGGACAGAT-3' \\
\hline$\beta$-globin-probe & 5'-FAM-TCTACCCTTGGACCCAGAGGTTCTTTGAGTTAMRA-3' \\
\hline
\end{tabular}

qPCR, quantitative polymerase chain reaction; FAM, 6-carboxyfluorescein; TAMRA, tetramethylrhodamine.

against the logarithm of the standard curve. The physical status of HPV-16 was assessed based on a previously published method (7,15). The total E6 copy number in $50 \mathrm{ng}$ cellular DNA was then determined (15). Ratios of E2 copy number/total E6 of $<1$ indicate the presence of both integrated and episomal forms. An $E 2 / E 6$ ratio $\geq 1$ indicates the predominance of the episomal form, whereas a ratio of 0 indicates the presence of the integrated form only.

ISH with HPV DNA probes. Biotinyl tyramide-based ISH was performed using the GenPoint ${ }^{\mathrm{TM}}$ HPV biotinylated DNA probe and the GenPoint tyramide signal amplification system for biotinylated probes according to the manufacturer's protocol (Dako; Agilent Technologies, Inc., Santa Clara, CA, USA). The GenPoint HPV biotinylated DNA probe has been found to react with HPV types 16, 18, 31, 33, 35, 39, $45,51,52,56,58,59$ and 68 in FFPE sections by ISH. Serial $4-\mu \mathrm{m}$-thick sections of FFPE samples were deparaffinized in xylene and rehydrated using a graded alcohol series. Target HPV DNA retrieval was performed in $10 \mathrm{mM}$ sodium citrate (at $\mathrm{pH} 6.0$ ) at $95^{\circ} \mathrm{C}$ for $40 \mathrm{~min}$. The slides were digested with proteinase K (10,000-fold dilution with Tris-buffered saline; Dako; Agilent Technologies, Inc.) for $10 \mathrm{~min}$ at room temperature. Endogenous peroxidases were blocked with $0.3 \% \mathrm{H}_{2} \mathrm{O}_{2}$ in methanol for $20 \mathrm{~min}$. A drop of the HPV probe was added to the section and a coverslip was applied. The probe and the target DNA were denatured by incubating the slides at $92^{\circ} \mathrm{C}$ for $5 \mathrm{~min}$. Following denaturation, the slides were transferred to a humidified chamber for hybridization at $37^{\circ} \mathrm{C}$ for $16 \mathrm{~h}$. Next, coverslips were removed and slides were bathed in TBS containing $0.05 \%$ Tween-20 (TBST). Coverslips were then washed using GenPoint Detection system stringent wash solution (Dako; Agilent Technologies, Inc.) at $48^{\circ} \mathrm{C}$ for $30 \mathrm{~min}$, followed by a rinse in TBST. Detection of the hybridized probe was performed using the GenPoint Detection system according to the manufacturer's protocol, with included primary streptavidin-horseradish peroxidase (HRP), biotinyl tyramide, secondary streptavidin-HRP and 3-3'-diaminobenzidine (DAB; Dako; Agilent Technologies, Inc.). Slides were counterstained with hematoxylin.

Immunohistochemistry for p16 $16^{I N K 4 a}$. Immunohistochemistry for p16 ${ }^{\text {INK4a }}$ was performed using the CINTec ${ }^{\circledR}$ p16 Histology kit (MTM Laboratories; Roche Applied Science, Penzberg, Germany) (19). Serial 4- $\mu$ m-thick sections of FFPE samples were deparaffinized in xylene and rehydrated in a graded alcohol series, followed by heating at $95-99^{\circ} \mathrm{C}$ for $10 \mathrm{~min}$ in kit epitope-retrieval solution. Endogenous peroxidases were blocked with kit peroxidase-blocking reagents at room temperature for $5 \mathrm{~min}$. The sections were incubated for $30 \mathrm{~min}$ at room temperature with primary monoclonal mouse anti-p16 ${ }^{\mathrm{INK} 4 \mathrm{a}}$ antibody (ready-to-use antibody solution) from the aforementioned 


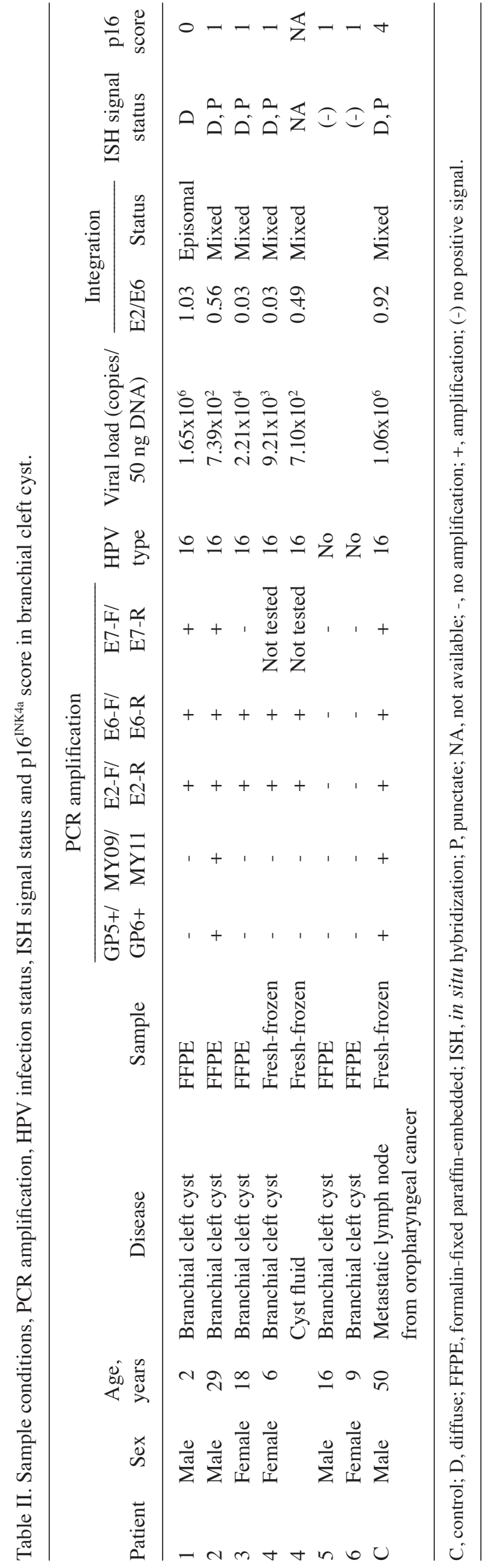

kit. Following washes in PBS, slides were incubated at room temperature for $30 \mathrm{~min}$ with HRP-conjugated goat anti-mouse secondary antibody (MTM Laboratories; Roche Applied Science). Immunolabeling was visualized following incubation in DAB at room temperature for $10 \mathrm{~min}$. Stained slides were counterstained with hematoxylin to visualize cyst structures for analysis under light microscopic observation.

The scoring criteria for $\mathrm{p} 16^{\mathrm{INK} 4 \mathrm{~A}}$ immunoreactivity (p16 ${ }^{\text {INK4A }}$ expression) were defined for the present study based on a previous scoring method (19): 0 , no staining; $1,1-10 \%$ of the tumor cells positive; $2,11-40 \%$ positive; $3,40-70 \%$ positive; and $4,>70 \%$ positive. The term 'p16 ${ }^{\mathrm{INK} 4 \mathrm{~A}}$ overexpression' was defined as a score of 3 or 4 .

\section{Results}

Identification of HPV types and analysis of the physical status of HPV-16. Table II presents the results of PCR using primer sets GP5+/GP6+, MY09/MY11, E2-F/E2-R, E6-F/E6-R and E7-F/E7-R. Primer sets GP5+/GP6+ and MY09/MY11 did not amplify the HPV genome effectively, unlike the E2-F/E2-R and E6-R/E6-R sets. PCR amplification, and the nucleotide sequences of the PCR products generated, demonstrated that 4/6 patients with BRCC were positive for HPV-16 (66.7\%), as was the patient with OPC. HPV-16 genomic DNA was also detected in the cyst fluid obtained from patient 4 using PCR.

Viral load and physical status of HPV-16. qPCR revealed HPV-16 loads (Table II). In the lymph node metastasis from the OPC case, the HPV-16 load was $1.06 \times 10^{6}$ copies $/ 50$ ng genomic DNA, whereas the loads in the four HPV-positive BRCCs ranged between $7.39 \times 10^{2}$ and $1.65 \times 10^{6}$ copies $/ 50$ ng DNA. Cyst fluid obtained from patient 4 was subjected to viral load analysis and was identified to have $7.10 \times 10^{2}$ copies $/ 50 \mathrm{ng}$ genomic DNA.

Since there were no marked differences between the amplification efficiencies of E2 (88.1\%) and E6 (89.7\%) PCR, the qPCR conditions in the present study were deemed suitable for evaluating integration. Analysis of the E2/E6 ratio demonstrated that one patient with BRCC (patient 1) had an episomal-type infection, whereas three mixed-type (episomal- and integrated-type) infections were noted in the three HPV-positive BRCCs (patients 2, 3 and 4) and in the lymph node of the patient with OPC.

ISH for identification of HPV DNA. Positive HPV DNA signals were observed in cyst wall tissues in 4/6 patients with BRCC (66.7\%; Table II, Figs. 1-3). Positive ISH was only observed in samples in which the HPV-16 genome was detected using PCR. Diffuse reactions in the nuclei of the basal to granular layers, particularly in prickle cells, were observed in patient 1 , who had an episomal-type HPV infection (Fig. 1). Fig. 1D shows diffuse ISH signals in the nuclei of prickle cells. Although the basal cells displayed diffuse reactions in the nuclei, positive reactions were also observed outside the nuclei (false-positive reactions; Fig. 1D). By contrast, both diffuse (red arrows) and punctate patterns (black arrows) were observed in the nuclei of the basal-to-granular layers in patients 2,3 and 4, and in those of the OPC case (Table II, Figs. 2 and 4). However, there was no positive ISH signal in patients 5 and 6 , who did not have HPV infection (Fig. 3C and D). 


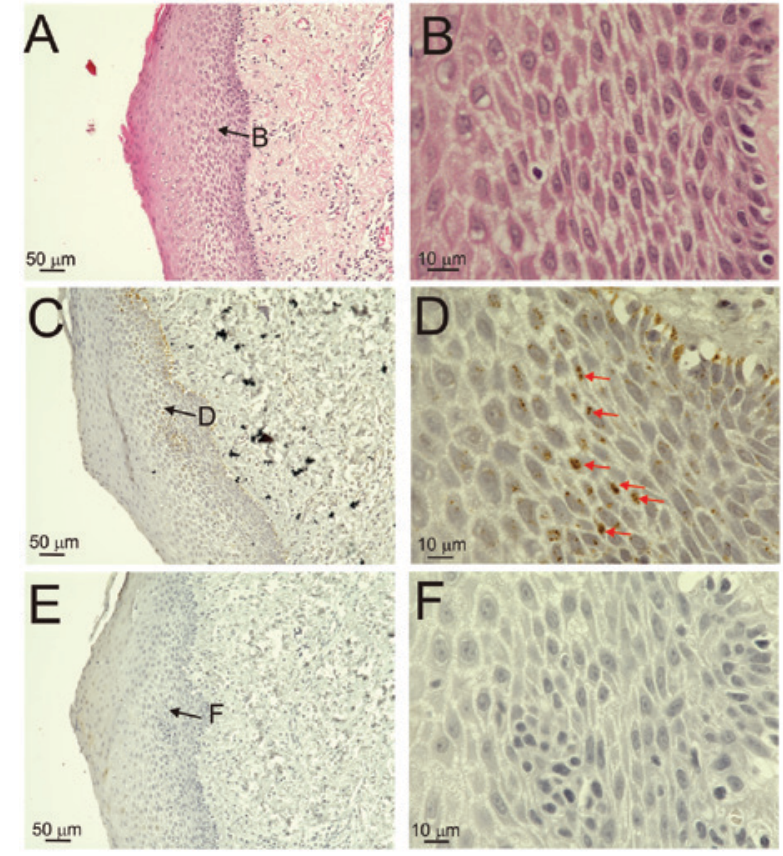

Figure 1. Histology results in patient 1 with episomal-type human papillomavirus-16 infection. (A and B) Hematoxylin and eosin staining; (C and D) in situ hybridization (red arrows indicate a diffuse in situ hybridization signal); and ( $\mathrm{E}$ and $\mathrm{F}$ ) immunohistochemical staining for $\mathrm{p} 16^{\mathrm{INK} 4 \mathrm{a}}$ (A, C and E) Scale bar, $50 \mu \mathrm{m}$; and (B, D and F) scale bar, $10 \mu \mathrm{m}$.
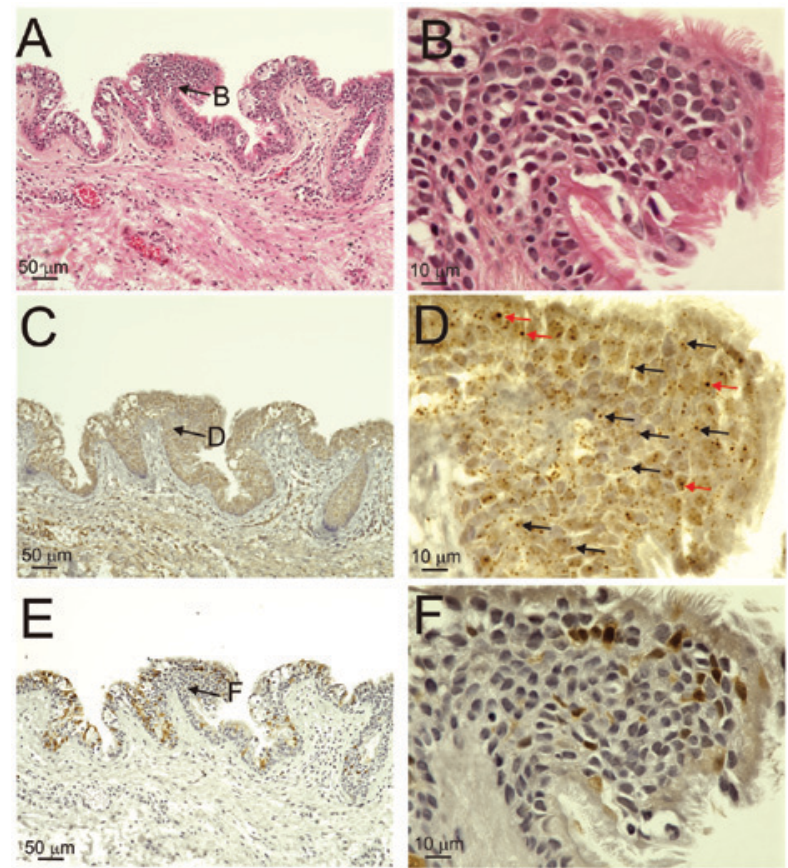

Figure 2. Histology results in patient 4 with mixed-type human papillomavirus-16 infection. (A and $\mathrm{B}$ ) Hematoxylin and eosin staining; (C and D) in situ hybridization at (black and red arrows indicate punctate and diffuse signals, respectively); and ( $\mathrm{E}$ and $\mathrm{F}$ ) immunohistochemical staining for p16 ${ }^{\mathrm{INK} 4 \mathrm{a}}$. (A, C and E) Scale bar, $50 \mu \mathrm{m}$; and (B, D and F) scale bar, $10 \mu \mathrm{m}$.

p16 INK4a immunoreactivity. The expression of $\mathrm{p} 16^{\mathrm{INK4a}}$ was weak in the nuclei and/or cytoplasm in the basal-to-keratinized layers of the cyst wall (score 1) in the three patients with BRCC with mixed-type infections (Table II, Fig. 2E and F), whereas the OPC case exhibited $\mathrm{p} 16^{\mathrm{INK} 4 \mathrm{a}}$ overexpression

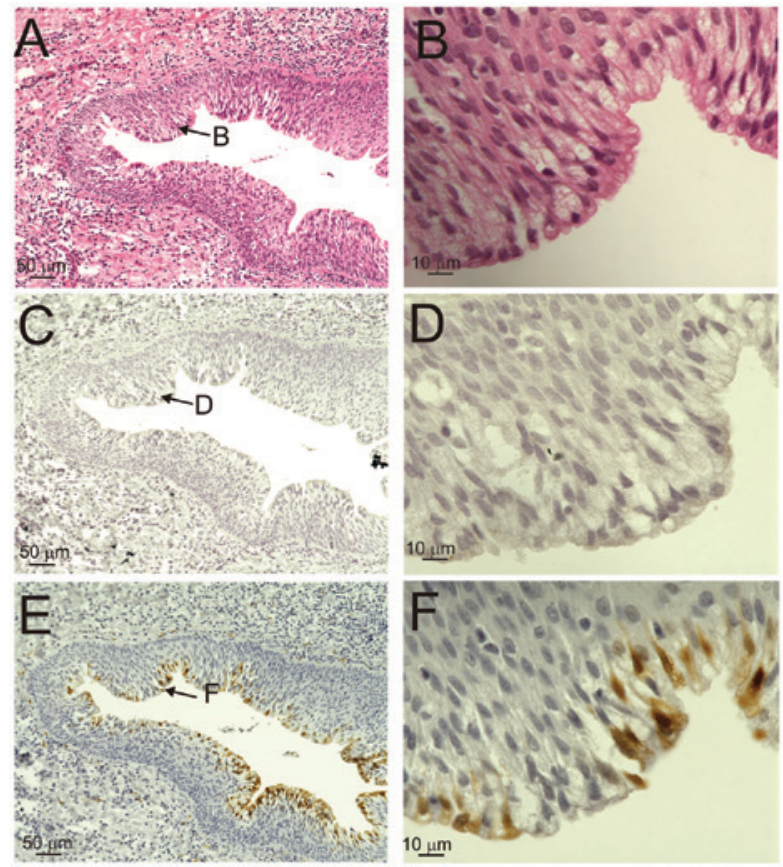

Figure 3. Histology results in patient 6, lacking human papillomavirus-16 infection. (A and B) Hematoxylin and eosin staining; (C and D) in situ hybridization; and (E and F) immunohistochemical staining for $\mathrm{p}^{1 \mathrm{INK} 4 \mathrm{a}}$. (A, C and E) Scale bar, $50 \mu \mathrm{m}$; and (B, D and F) scale bar, $10 \mu \mathrm{m}$.
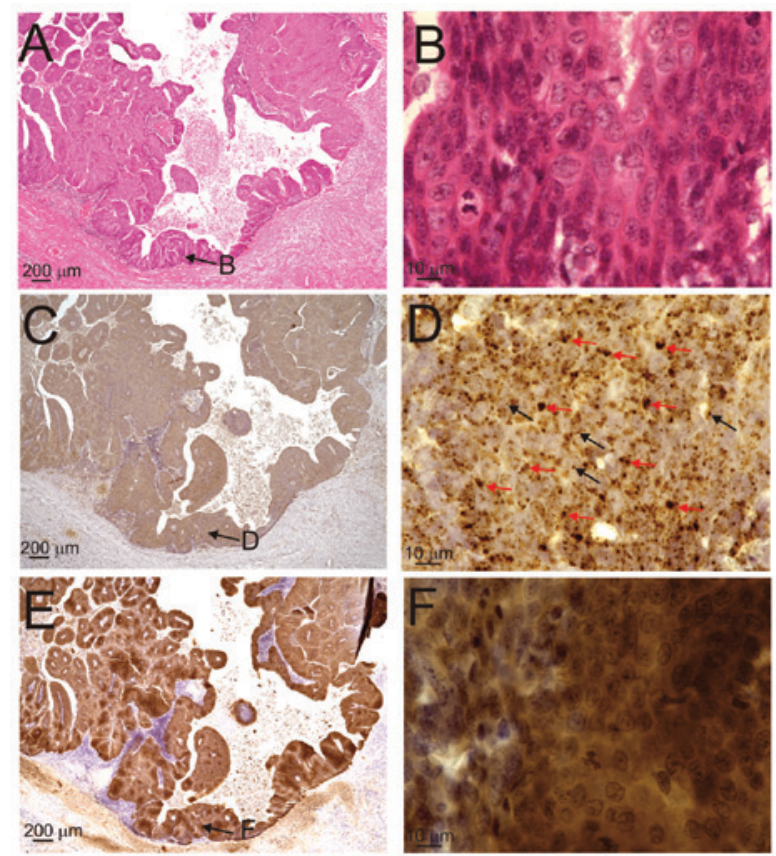

Figure 4. Histology results in the metastatic lymph node of a patient with HPV-associated oropharyngeal cancer (positive control). (A and B) Hematoxylin and eosin; (C and D) in situ hybridization (black and red arrows indicate punctate and diffuse signals, respectively); and (E and F) immunohistochemical staining for $\mathrm{p} 16^{\mathrm{INK} 4 \mathrm{a}}$. HPV, human papillomavirus. (A, C and E) Scale bar, $200 \mu \mathrm{m}$; and (B, D and F) scale bar, $10 \mu \mathrm{m}$.

(Fig. 4E and F; score 4). The superficial cyst-lining squamous cells of the cyst wall in specimens from patients 5 and 6 (who did not have HPV infection) also exhibited faint immunoreactivity (Fig. 3E and F; score 1). On the other hand, the specimen from patient 1 , who had an episomal infection, exhibited 
no $16^{\mathrm{INK} 4 \mathrm{a}}$ immunoreactivity (Fig. 1E and F; score 0). Since $5 / 6$ patients with patients with BRCC exhibited a weak p16 $6^{\mathrm{INK} 4 \mathrm{a}}$ reaction in the cyst wall, the expression of $\mathrm{p} 16^{\mathrm{INK} 4 \mathrm{a}}$ was not associated with the presence of HPV detected by PCR.

\section{Discussion}

In the present study, HPV-16 genome DNA was detected in 4/6 samples from patients with BRCC using PCR with HPV-16-specific primers. However, HPV-16 genome was detected in only one using PCR using the consensus primers. Paraffin fixation of samples induces DNA fragmentation and can occasionally result in a false-negative PCR result (17). FFPE samples of BRCCs were examined by PCR using consensus primers (GP5+/GP6+ and MY09/MY11), except in the case of patient 4 . A previous study concerning HPV infection in BRCCs demonstrated that 7 of 19 BRCCs (36.8\%) contained high-risk HPV-16 and/or HPV-18 genomes (12). In that study, FFPE samples were examined and the GP5+/GP6+ PCR primer set was used to detect the HPV genome in the samples from patients with BRCC (12). The divergent results, which reveal a difference in the presence of HPV between the present study and the previous study (12) may relate to the PCR method and sample conditions (i.e., whether the sample was fresh-frozen or FFPE). In a previous study of head and neck squamous cell carcinomas using fresh-frozen samples (13), HPV-16 genome DNA was detected via PCR using consensus primers in 39/45 (86.7\%) squamous cell carcinoma samples infected with high-risk type HPV subtypes. Since HPV-16 is the major HPV type present in head and neck carcinomas, specific primers for HPV-16 were used in the present PCR analysis. ISH with the HPV DNA probes used in the present study can react with HPV types $16,18,31,33,35,39,45,51$, 52, 56, 58, 59 and 68 in FFPE sections. The consistent results between PCR and ISH experiments suggest that HPV-16 is a major type of HPV infection in BRCC.

In a previous study (15), the viral load of HPV-16 in tonsillar carcinomas ranged between $1.54 \times 10^{2}$ and $1.34 \times 10^{7}$ (median, $\left.4.13 \times 10^{5}\right)$, and was significantly increased compared with that in non-tonsillar head and neck carcinomas $\left(1.20 \times 10^{1}-3.89 \times 10^{6}\right.$; median, $\left.9.7 \times 10^{1}\right)$, detected using the same methods as those used in the present study. The HPV-16-positive BRCC samples in the present study had decreased viral loads $\left(7.10 \times 10^{2}-1.65-10^{6}\right.$; median, $\left.9.21 \times 10^{3}\right)$ compared with the tonsillar carcinomas in the previous study (15), and patients with BRCC with integration of HPV genome had decreased viral loads compared with the metastatic lymph node from the OPC case (Table II, control case).

The integration of DNA from high-risk HPV types into the host genome is a major step in malignant transformation $(6,8)$. In the present study, viral integration was observed in three of four BRCC samples with HPV infection. The punctate and diffuse HPV DNA ISH staining patterns corresponded to integrated- and episomal-type infections, respectively (20). Therefore, the consistent results of the physical status of HPV infection in ISH- and PCR-based HPV detection in the present study indicated that persistent high-risk type HPV infections may occur in patients with BRCC. In the present study, immunoreactive $\mathrm{p} 16^{\mathrm{INK4a}}$ was weakly expressed, regardless of HPV infection (Table II and Fig. 3). Pai et al (12) reported that p16 $6^{\mathrm{INK} 4 \mathrm{~A}}$ expression in the superficial BRCC cyst-lining cells may represent the process of cellular senescence prior to the shedding of cells into the cyst lumen. Although the functional inactivation of host $\mathrm{pRb}$ by HPV protein $\mathrm{E} 7$ results in the overexpression of $\mathrm{p} 16^{\mathrm{INK} 4 \mathrm{a}}$, weak $\mathrm{p} 16^{\mathrm{INK} 4 \mathrm{a}}$ expression, despite the mixed integration of HPV-16, might represent low E7 expression and a low BRCC viral load. These results also suggest that the weak expression of $\mathrm{p} 16^{\mathrm{INK} 4 \mathrm{a}}$ observed in the present study may not be an indicator of HPV infection.

In the present study, none of the patients with BRCC had fistulas, either externally or internally, but high-risk type HPV genomic DNA was present. Further study is required to clarify the route of HPV infection. A possible explanation for HPV infection in BRCC might be the entry of the virus through the branchial groove and/or pouch via amniotic fluid in the prenatal period. There have been several reports demonstrating the presence of HPV DNA in the amniotic fluid of pregnant women (21-25). The presence of HPV DNA in the amniotic fluid and/or placenta increases the risk of HPV infection in the neonate at birth $(21,22)$. Possible perinatal vertical HPV transmission is suspected, because cesarean section delivery does not protect against mother-to-child HPV transmission (25). These previous studies suggest that neonates have early contact with HPV prior to delivery. The most commonly detected HPV types in the amniotic fluid are HPV-6, -11, -16 and -18 (26-29). The most prevalent HPV type in asymptomatic oral infections is HPV-16, followed by HPV-6 and -11 $(30,31)$. In the present study, the HPV DNA detected in the cyst wall and cyst fluid of BRCC cases was the high-risk subtype HPV-16. These results are consistent with reports concerning the HPV types observed in amniotic fluid (21-25). Since the participants in the present study were young (2-29 years), vertical infection was the most likely route of HPV infection in these BRCC cases, although whether the HPV genome is present in the amniotic fluid remains unknown.

Although BRCC is usually treated with surgical excision, several studies recommend sclerotherapy as the primary treatment $(32,33)$. The results of these studies indicate that sclerotherapy for cystic neck lesions has a satisfactory outcome, lower morbidity and fewer complications compared with surgical treatment. However, imaging modalities and even aspiration cytology cannot sufficiently differentiate between benign and malignant cysts. Since lymph node metastasis from OPC may appear as a cystic mass $(20,34)$ and certain patients with BRCC exhibit persistent high-risk-type HPV infection, as observed in the present study, these issues should be taken into account when considering sclerotherapy for BRCC. Since the HPV genome in the cystic fluid of BRCC may be amplified by PCR in the present study, this method may aid the detection of HPV infection.

In summary, high-risk-type HPV infection was frequently observed in patients with BRCC. To the best of our knowledge, the present study is the first to demonstrate that HPV integration occurs in BRCC. Since a considerable number of patients with BRCC exhibit persistent infection and integration of high-risk-type HPV DNA, surgical treatment may be more beneficial in these cases. Further studies are required to clarify the clinical relevance of infection with high-risk HPV types to the etiology and malignant transformation of BRCC. 


\section{Acknowledgements}

The authors would like to thank the Ryukyu Society for the Promotion of Oto-Rhino-Laryngology for providing assistance with writing and for technical assistance.

\section{Funding}

This study was supported by a KAKENHI grant (no. 26462610) awarded by the Japan Society for the Promotion of Science.

\section{Availability of data and materials}

All data generated and analyzed during this study are included in this published article.

\section{Authors' contributions}

TI and TU contributed to the experimental studies, data acquisition and preparation of the manuscript. ZD contributed to the experiments and data acquisition. SK, HM, AK, SA, HH, YY and AG contributed to the acquisition of samples and to surgical treatment. MS contributed to the study design, supervision of experiments and manuscript review. All authors read and approved the final manuscript.

\section{Ethics approval and consent to participate}

The present study was approved by the Ethics Committee of the University of the Ryukyus (Nakagami, Japan). All patients provided written informed consent to participate prior to surgery. Procedures were performed in accordance with the Declaration of Helsinki.

\section{Consent for publication}

Not applicable.

\section{Competing interests}

The authors declare that they have no competing interests.

\section{References}

1. Waldhausen JH: Branchial cleft and arch anomalies in children. Semin Pediatr Surg 15: 64-69, 2006.

2. Veivers D and Dent J: Lateral cervical cysts: An Australian perspective. ANZ J Surg 82: 799-802, 2012.

3. Bzhalava D, Eklund C and Dillner J: International standardization and classification of human papillomavirus types. Virology 476: 341-344, 2015.

4. Clifford GM, Smith JS, Plummer M, Munoz N and Franceschi S: Human papillomavirus types in invasive cervical cancer worldwide: A meta-analysis. Br J Cancer 88: 63-73, 2003.

5. Jacobs MV, Snijders PJ, van den Brule AJ, Helmerhorst TJ, Meijer CJ and Walboomers JM: A general primer GP5+/GP6(+) mediated PCR-enzyme immunoassay method for rapid detection of 14 high-risk and 6 low-risk human papillomavirus genotypes in cervical scrapings. J Clin Microbiol 35: 791-795, 1997.

6. Badaracco G, Venuti A, Sedati A and Marcante ML: HPV16 and HPV18 in genital tumors: Significantly different levels of viral integration and correlation to tumor invasiveness. J Med Virol 67: 574-782, 2002.
7. Peitsaro P, Johansson B and Syrjänen S: Integrated human papilloma virus type 16 is frequently found in cervical cancer precursers as demonstrated by a novel quantitative real time PCR technique. J Clin Microbiol 40: 886-891, 2002.

8. Arias-Pulido H, Peyton CL, Joste NE, Vargas H and Wheeler CM: Human papillomavirus type 16 integration in cervical carcinoma in situ and in invasive cervical cancer. J Clin Microbiol 44: 1755-1762, 2006.

9. Khleif SN, DeGregori J, Yee CL, Otterson GA, Kaye FJ, Nevins JR and Howley PM: Inhibition of cyclin D-CDK4/CDK6 activity is associated with an E2F-mediated induction of cyclin kinase inhibitor activity. Proc Natl Acad Sci USA 93: 4350-4354, 1996.

10. Serrano M, Hannon GJ and Beach D: A new regulatory motif in cell-cycle control causing specific inhibition of cyclin D/CDK4. Nature 366: 704-707, 1993.

11. Jeon S and Lambert PF: Integration of human papillomavirus type 16 DNA into the human genome leads to increased stability of E6 and E7 mRNAs: Implications for cervical carcinogenesis. Proc Natl Acad Sci USA 92: 1654-1658, 1995.

12. Pai RK, Erickson J, Pourmand N and Kong CS: p16INK4A immunohistochemical staining may be helpful in distinguishing branchial cleft cysts from cystic squamous cell carcinomas originating in the oropharynx. Cancer 117: 108-119, 2009.

13. Deng Z, Hasegawa M, Matayoshi S, Kiyuna A, Yamashita Y, Maeda $\mathrm{H}$ and Suzuki M: Prevalence and clinical features of human papillomavirus in head and neck squamous cell carcinoma in Okinawa, southern Japan. Eur Arch Otorhinolaryngol 268: 1625-1631, 2011.

14. Taga M, Eguchi H, Shinohara T, Takahashi K, Ito R, Yasui W, Nakachi K, Kusunoki Y and Hamatani K: Improved PCR amplification for molecular analysis using DNA from long-term preserved formalin-fixed, paraffin-embedded lung cancer tissue specimens. Int J Clin Exp Pathol 6: 76-79, 2013.

15. Deng Z, Hasegawa M, Kiyuna A, Matayoshi S, Uehara T, Agena S, Yamashita Y, Ogawa K, Maeda $\mathrm{H}$ and Suzuki M: Viral load, physical status, and E6/E7 mRNA expression of human papillomavirus in head and neck squamous cell carcinoma. Head Neck 35: 800-808, 2013.

16. Deng Z, Hasegawa M, Yamashita Y, Matayoshi S, Kiyuna A, Agena S, Uehara T, Maeda H and Suzuki M: Prognostic value of human papillomavirus and squamous cell carcinoma antigen in head and neck squamous cell carcinoma. Cancer Sci 103: 2127-2134, 2012.

17. Specht K, Richter T, Müller U, Walch A, Werner M and Höfler H: Quantitative gene expression analysis in microdissected archival formalin-fixed and paraffin-embedded tumor tissue. Am J Pathol 158: 419-429, 2001.

18. van Duin M, Snijders PJF, Schrijnemakers HFJ, Voorhorst FJ, Rozendaal L, Nobbenhuis MAE, van den Brule AJC, Verheijen RHM, Helmerhorst TJ and Meijer CJ: Human papillomavirus 16 load in normal and abnormal cervical scrapes: An indicator of CIN II/III and viral clearance. Int J Cancer 98: 590-595, 2002.

19. Deng Z, Hasegawa M,AokiK, Matayoshi S, Kiyuna A, Yamashita Y, Uehara T, Agena S, Maeda H, Xie M and Suzuki M: A comprehensive evaluation of human papillomavirus positive status and $\mathrm{p} 16^{\mathrm{INK} 4 \mathrm{a}}$ overexpression as a prognostic biomarker in head and neck squamous cell carcinoma. Int J Oncol 45: 67-76, 2014.

20. Evans MF, Mount SL, Beatty BG and Cooper K: Biotinyltyramide-based in situ hybridization signal patterns distinguish human papillomavirus type and grade of cervical intraepithelial neoplasia. Mod Pathol 15: 1339-1347, 2002.

21. Armbruster-Moraes E, Ioshimoto LM, Leão E and Zugaib M: Presence of human papillomavirus DNA in amniotic fluids of pregnant women with cervical lesions. Gynecol Oncol 54: 152-158, 1994.

22. Sarkola ME, Grénman SE, Rintala MA, Syrjänen KJ and SyrjäNen SM: Human papillomavirus in the placenta and umbilical cord blood. Acta Obstet Gynecol Scand 87: 1181-1188, 2008.

23. Syrjänen S: Current concepts on human papillomavirus infections in children. APMIS 118: 494-509, 2010.

24. Tseng CJ, Lin CY, Wang RL, Chen LJ, Chang YL, Hsieh TT and Pao CC: Possible transplacental transmission of human papillomaviruses. Am J Obstet Gynecol 166: 35-40, 1992.

25. Smith EM, Johnson SR, Cripe TP, Pignatari S and Turek L: Perinatal vertical transmission of human papillomavirus and subsequent development of respiratory tract papillomatosis. Ann Otol Rhinol Laryngol 100: 479-483, 1991. 
26. Cason J and Mant CA: High-risk mucosal human papillomavirus infections during infancy \& childhood. J Clinical Virology 32 (Suppl 1): S52-S58, 2005.

27. Fredericks DB, Balkin A, Daniel HW, Schonrock J, Ward B and Frazer IH: Transmission of human papillomaviruses from mother to child. Aust NZJ Obstet Gynaecol 33: 30-32, 1993.

28. Kaye JN, Cason J, Pakarian FB, Jewers RJ, Kell B, Bible J, Raju KS and Best JM: Viral load as a determinant for transmission of human papillomavirus type 16 from mother to child. J Med Virol 44: 415-421, 1994.

29. Pakarian F, Kaye J, Cason J, Kell B, Jewers R, Derias NW, Raju KS and Best JM: Cancer associated human papillomaviruses: Perinatal transmission and persistence. Br J Gynaecol Obstet 101: 514-517, 1994.

30. Syrjänen S: HPV infections in children. Papillomavirus Rep 14: 93-110, 2003

31. Syrjänen $S$ and Puranen M: Human papillomavirus infections in children: The potential role of maternal transmission. Crit Rev Oral Biol Med 11: 259-274, 2000.
32. Kim MG, Kim SG, Lee JH, Eun YG and Yeo SG: The therapeutic effect of OK-432 (picibanil) sclerotherapy for benign neck cysts. Laryngoscope 118: 2177-2181, 2008.

33. Knipping S, Goetze G, Neumann K and Bloching M: Sclerotherapy of cervical cysts with Picibanil (OK-432). European Archives of Oto-Rhino-Laryngology 264: 423-427, 2007.

34. Yasui T, Morii E, Yamamoto Y, Yoshii T, Takenaka Y, Nakahara S, Todo $\mathrm{T}$ and Inohara H: Human papillomavirus and cystic node metastasis in oropharyngeal cancer and cancer of unknown primary origin. PLoS One 9: e95364, 2014.

(C) $\Theta$ This work is licensed under a Creative Commons Attribution-NonCommercial-NoDerivatives 4.0 International (CC BY-NC-ND 4.0) License. 